\title{
A INFLUÊNCIA SOBRE OS INGRESSANTES NA ESCOLHA DO CURSO SUPERIOR DE ADMINISTRAÇÃO
}

\author{
THE INFLUENCE ON MEMBERS IN CHOOSING THE HIGHER ADMINISTRATION COURSE
}

Antonio Carlos de Lima Filho ${ }^{1}$

Submetido em: 10/07/2020

Avaliado em: 08/12/2020

Aprovado em: 09/02/2021

\section{RESUMO}

Apesar do crescimento no número de cursos superiores ao longo dos últimos anos, não é fácil a decisão para quem escolhe fazer um curso superior, em outras palavras escolher qual curso cursar, para trilhar sua carreira profissional. Desta forma alguns se deixam levar pela a influência seja ela de familiares, amigos ou colegas de trabalho. Este trabalho mostra o quanto esses influenciadores podem decidir na escolha do curso de um ingressante ao ensino superior, mostra também que a idade nesse caso não é um fato determinante para se deixar ser influenciado, vendo que os ingressantes de hoje são na maioria jovens que estão saindo do ensino médio com idade menor que 25 anos. O objetivo do trabalho é mostrar a influência que os ingressantes sofrem ou não na escolha do curso de Administração, mostrando resultados verídicos de alunos ingressantes do curso em questão.

PALAVRAS-CHAVE: : Decisão. Escolha. Influência. Influenciadores. Ingressantes.

\section{ABSTRACT}

Despite the growth in the number of higher education courses over the past few years, it is not an easy decision for those who choose to take a higher education course, in other words to choose which course to take, to pursue their professional career. In this way, some are carried away by the influence of family, friends or co-workers. This work shows how much these influencers can decide when choosing a course for a student entering higher education, it also shows that age in this case is not a determining factor in allowing oneself to be influenced, seeing that today's students are mostly young people who are leaving high school under the age of 25 . The objective of the work is to show the influence that the freshmen suffer or not in the choice of the Administration course, showing true results of students entering the course in question.

KEYWORDS: Decision. Choice. Influence. Influencers. Newcomers.

\footnotetext{
${ }^{1}$ Especialista em Gestão Empresarial, Especialista em Automação Industrial. Graduado em Administração, Licenciado em Mecânica e Tecnólogo em Sistemas Biomédicos.Atualmente é Coordenador e professor dos cursos de Administração, Ciências Contábeis e Gestão de Recursos Humanos, da UNINASSAU Maceió. Também é professor dos cursos de Engenharia Elétrica e Engenharia Mecânica da mesma instituição.
} 


\section{INTRODUÇÃO}

A escolha de um curso dentre tantos os oferecidos podem ser fáceis para alguns em um primeiro momento. Porém, para muitos alunos que ingressam na universidade tendem a, em algum momento, terem dúvidas quanto à escolha que fizeram. MORAES, (2017) afirma que etapa de formação universitária pode desencadear crises vocacionais, de confrontação com a realidade $e$ de certificação da escolha feita.

Certos temas podem/servir de gatilho para estas crises vocacionais, como por exemplo, questionar-se quanto à sua capacidade intelectual, quanto às metodologias de ensino, permanecer em estado de dúvida quanto às probabilidades de sucesso futuro na área escolhida. Estes e outros assuntos integram questionamentos frequentes dos discentes de ensino superior.

Os alunos questionam-se também quanto à capacidade dos professores na transmissão do conhecimento no curso escolhido, pois há situações em que os discentes afirmam que amigos que já fazem o curso não compreendem as informações transmitidas, o que pode ser uma agravante que tende a levar a uma possível desistência na escolha do curso (MORAES, 2017).

Não é diferente para quem decide estudar Administração de Empresas no Brasil, onde tem sido intensa essa discussão sobretudo para quem pretende cursar essa graduação. Muitos problemas são levantados e analisados, e a partir daí surgem as dúvidas e as influencias sobre se realmente é esse curso que se deve escolher.

Uma das questões relevantes, e levada em consideração por quem pretende cursar Administração de Empresas é que o curso já está formulado e reconhecido pelo Ministério da Educação, não é um curso novo o que está sendo implantado agora, sem falar que as Instituições de Ensino Superior (IES) têm seguido fielmente a proposta contida em seus projetos pedagógicos, o que prepara o aluno cada vez mais para o mercado de trabalho.

Contudo, há de se considerar que as influências não são afetos somente de pessoas próximas mas também de pessoas que só de ouvir o estudante mencionar em cursar Administração já diz sua opinião sobre o curso, porquanto o aluno do curso de Administração, em grande parte, principalmente àqueles do turno da noite já tem uma idade onde já tem sua opinião formada sobre o curso (LOPES, 2008).

\section{METODOLOGIA}

Segundo Teodoro (2009) metodologia de ensino é um conjunto de métodos aplicados para a aprendizagem de alunos, ações e postura do professor para que este transmita conhecimentos aos discentes.

Este trabalho estrutura-se em uma pesquisa com abordagem qualitativa, por ser capaz de entender a subjetividade das questões aqui exploradas. A pesquisa qualitativa trabalha com valores, opiniões, hábitos, e outras informações subjetivas, tratando os dados particulares do entrevistado cuidadosamente, garantindo a veracidade das respostas (MINAYO, 1996).

Com o objetivo de trabalhar com as informações sobre o tema proposto, define-se que a pesquisa exploratória é a escolha ideal para a precisão que se busca. Conforme Gil (2010, p. 27) este tipo de pesquisa explicita melhor o problema podendo utilizar como ferramenta de apoio levantamentos bibliográficos e entrevista com os alunos. Ao final da pesquisa exploratória espera-se ter um aprofundamento em seu objeto de estudo, sendo capaz de formular hipóteses (GIL, 2010).

A ferramenta investigativa escolhida para este trabalho foi o modelo de entrevista em profundidade por ser uma das maneiras mais eficazes para se entender e descrever de várias maneiras os fenômenos observados (CURVELLO, 2002). Este tipo de entrevista fornece elementos que favorecem a compreensão de determinada situação a fim de investigar como esta é percebida pelos entrevistados. As entrevistas são conduzidas através de um roteiro estruturado de questões semiabertas, que são questões que partem de um roteiro-base.

Conforme Manzini (2003) o roteiro tem como função principal possibilitar ao entrevistador, um planejamento prévio da coleta dos dados, oportunizando uma interação de maior qualidade entre entrevistador e entrevistado. Para que as perguntas sejam acessíveis a todos os entrevistados, algumas precauções são necessárias, como por exemplo, o cuidado com a linguagem, com o tipo de pergunta e quanto à sequência das perguntas (MANZINI, 2003).

As questões são originadas do problema de pesquisa e buscam tratar o tema central de uma maneira ampla. É de responsabilidade do entrevistador absorver todas as informações e perceber todos os detalhes 
fornecidos, mesmo que de maneira sutil e inconsciente pelo entrevistado, para que consiga assimilar a situação e por consequência perceber novas hipóteses a serem estudadas. Triviños (1990, p. 125) corrobora com este pensamento trazendo que parte de certos questionamentos básicos, apoiado em teorias e hipóteses que interessam à pesquisa, e que, em seguida, oferecem amplo campo de interrogativas, fruto de novas hipóteses que vão surgindo à medida que se recebem as respostas do informante.

O público alvo do presente estudo constitui-se de 100 alunos do curso de Administração de Empresas, ingressantes no ano de 2019.

A pesquisa contou apenas com três perguntas, a primeira era qual a idade do ingressante no curso de Administração? A segunda pergunta era a seguinte, houve influência de alguém para a escolha do curso de Administração de Empresas? Caso a resposta fosse não, a pesquisa terminaria na segunda pergunta, porém se a resposta fosse sim o aluno responderia a terceira e última pergunta, que era a seguinte, a influência foi de quem?

Dessa a forma a pesquisa ficou objetiva e direta com perguntas e respostas simples que o aluno teria como responder de imediato sem perder tempo e agilizar o processo do trabalho.

\section{RESULTADO}

Verificou-se que dos 100 alunos que participaram da pesquisa, as idades são muito variadas como pode ser visto no gráfico 01 .

Gráfico 1 - Mostra as idades dos 100 alunos entrevistados

Graphic 1 - Shows the ages of the 100 students interviewed

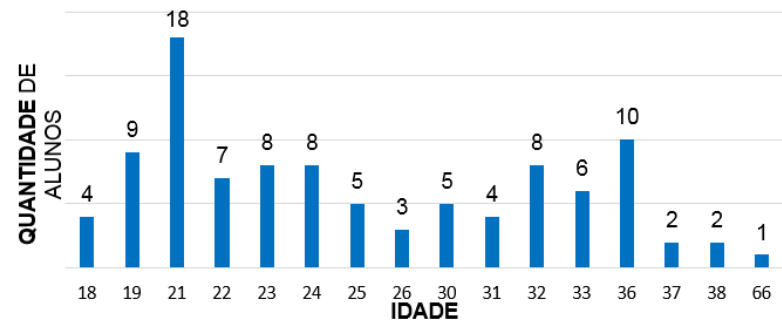

Fonte: Própria

Source: Own
O estudo mostrou que dos 100 estudantes entrevistados mais de $50 \%$ dos discentes que escolhem fazer administração tem uma idade inferior a 25 anos. Isso pode fazer com quer os discentes sofram alguma influência na hora da escolha de qual curso superior cursar devido a sua idade (CAVALHEIRO, 2018).

Verifica-se também que um pouco mais de $40 \%$ tem idade superior a 30 anos, dessa forma entende-se que já tem uma opinião formada sobre qual curso superior escolher, não deixando assim ser influenciado na sua escolha, isso levando em conta que as pessoas com mais de 30 anos já sabem qual profissão querem seguir ( (CAVALHEIRO, 2018).

Porém, quando perguntado se houve a influência de alguém, o resultado mostrou que a idade não está ligada diretamente a questão de se deixar ser influenciado na escolha da sua graduação, pois 62 dos ingressantes afirmaram que não tiveram influência de ninguém na escolha do seu curso superior, e 38 dos discentes afirmaram terem sido influenciados por alguém. 0 gráfico 2 mostra as afirmações ditas anteriormente.

Gráfico 2 - Quantidade de alunos influenciados para escolha do curso

Graphic 2 - Number of students influenced to choose the course

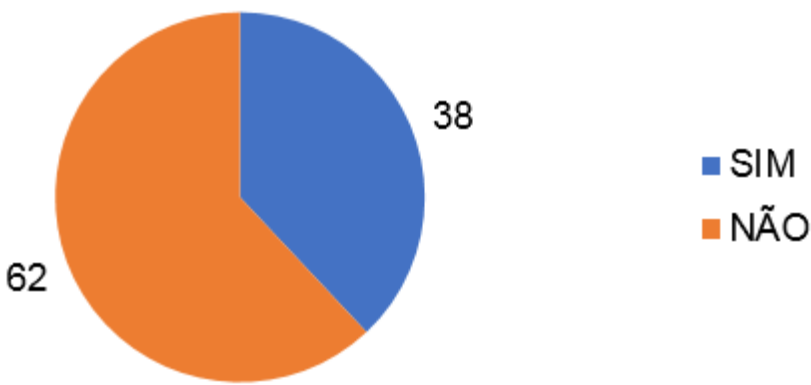

Fonte: Própria

Source: Own

Dos 38 discentes ingressantes que responderam que houve influência de alguém na escolha do seu curso, essa influência foi dos colegas de trabalho, amigos ou familiares, o gráfico 3 mostra os números de cada classe desses influenciadores. 
Gráfico 3 - Quantidade de alunos atingido por cada classe de influenciadores

Graphic 3 - Number of students reached by each class of influencers

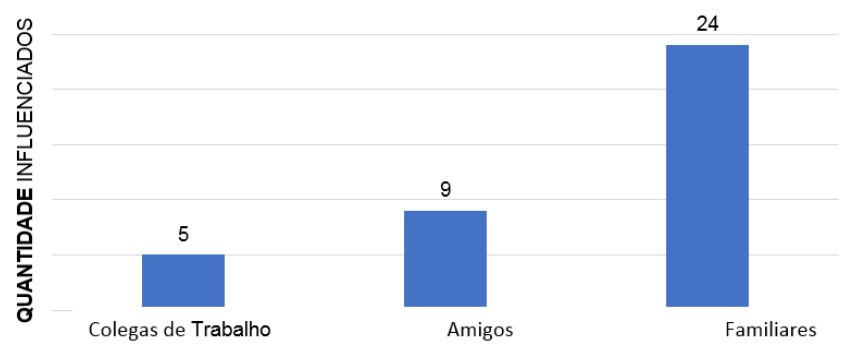

Fonte: Própria

Source: Own

Pegando os dados do gráfico 3 podemos ver que dos 38 influenciados $13,16 \%$ foram influenciados por seus colegas de trabalho, $23,68 \%$ por amigos e $63,16 \%$ foram influenciados por seus familiares. Desta forma fica claro que na classe dos influenciadores os familiares são quem mais tem o poder de influenciar os ingressantes no curso do ensino superior.

\section{CONSIDERAÇÕES FINAIS}

Ficou evidente no estudo que, alguns alunos ingressantes do curso de Administração sofrem alguma influência, e que essa influência é mais forte por parte dos familiares dos discentes, o que mostra que a família influencia na tomada de decisão.

A maioria dos entrevistados não julga necessário a opinião de alguém para que adotem qual graduação escolher. Com isso para os ingressantes no curso de Administração a decisão de escolher o curso pode ser por muitos motivos, mais não pela opinião de outra pessoa.

Com isso podemos concluir que alguns dos ingressantes no curso de Administração são influenciados. E no universo de 100 alunos ingressantes 62\% ingressam no curso por quer querem e acham que a profissão de administrador é uma profissão que sempre está em alta e por isso irão seguir e fazer carreira profissional.

\section{REFERÊNCIA}

ANDERSON, D. R.; SWEENEY, D. J.; WILLIAMS, T. A. Estatística aplicada à administração e economia. 2. ed. São Paulo: Cengage Learning, 2007.

AUGIER, M.; TEECE, D. J. Dynamic Capabilities and the Role of Managers in Business Strategy and Economic Performance. Organization Science, v. 20, n. 2, p. 410 421, 2009.

BENTO, A. Como fazer uma revisão da literatura: Considerações teóricas e práticas. Revista JA (Associação Académica da Universidade da Madeira), n. 65, p. 4244, 2012.

CAVALHEIRO, Maria Gabriela et al. O Que os Estudantes Consideram na Escolha do Curso de Graduação? Revista de Graduação USP, São Paulo, v. 3, n. 2, p. 63-69, jul. 2018.

COSTA NETO, P. L. O. Estatística. São Paulo: Edgard Blücher, 1977. 264 p.

CURVELLO, J. J. A. Comunicação interna e cultura organizacional. São Paulo: Scortecci, 2002.

HELFAT, C. E.; PETERAF, M. A. Managerial cognitive capabilities and the microfoun $\neg$ dations of dynamic capabilities. Strategic Management Journal, v. 36, n. 6, p. 831-850, 2015.

GIL, A. Como elaborar projetos de pesquisa. 5. ed. São Paulo: Atlas, 2010.

JACOBIDES, M. G.; WINTER, S. G. Capabilities: Structure, agency, and evolution. Organization Science, v. 23, n. 5, p. 1365-1381, 2012.

LOPES, R. C. S. A relação professor aluno e o processo ensino aprendizagem, 2008.

MANZINI, E. J. Considerações sobre a elaboração de roteiro para entrevista semiestruturada.

In: MARQUEZINE; M. C.; ALMEIDA, M. A.; OMOTE; S. (Org.) Colóquios sobre pesquisa em educação especial. Londrina: Eduel, 2003.

MINAYO, M. C. S. O desafio do conhecimento: pesquisa qualitativa em saúde. 4. ed. São Paulo: Hucitec, 1996. 
MORAES, Jhony Pereira; PAIM, Clarice da Fontoura. O ensino da administração: práticas pedagógicas e seus impactos no desempenho profissional na visão dos formandos de graduação em administração de uma instituição privada na cidade de Porto Alegre - RS. CAMINE: Caminhos da Educação = Camine: Ways of Education, Franca, v. 9, n. 2, p. 96-113, dez. 2017. ISSN 21754217. Disponível em: <https://ojs.franca.unesp.br/index. php/caminhos/article/view/2137>. Acesso em: $30 \mathrm{dez}$. 2019. doi:http://dx.doi.org/10.5016/camine.v9i2.2137.

TEODORO, N. M. Metodologia de ensino: uma contribuição pedagógica para o processo de aprendizagem da diferenciação. Maringá, 2009. Disponível em <http:// www.diaadiaeducacao.pr.gov.br/portals/pde/arquivos/2234-8.pdf>. Acesso em: 18 set. 2016.

TRIVIÑOS, A. N. S. Introdução à pesquisa em ciências sociais: a pesquisa qualitativa em educação. São Paulo: Atlas, 1990. 